\title{
Effect of Disulfiram/Copper Gluconate Combination on Haematological Indices in Rodents
}

\author{
Georgewill Udeme Owunari, Siminialayi Iyeopu Minakiri, Obianime Atuboyedia Wolfe \\ Department of Pharmacology, Faculty of Basic Medical Sciences, College of Health Sciences, University of Port \\ Harcourt, Port Harcourt, Nigeria \\ Email: udgeorgewill@yahoo.com
}

Received 20 December 2014; accepted 15 January 2015; published 20 January 2015

Copyright (C) 2015 by authors and Scientific Research Publishing Inc.

This work is licensed under the Creative Commons Attribution International License (CC BY). http://creativecommons.org/licenses/by/4.0/

(c) (7) Open Access

\section{Abstract}

The chronic toxicological profile of disulfiram/copper gluconate (DSF/CG) combination was investigated in a 90 day time and dose dependent study. A total of 148 rats weighing $260-300 \mathrm{~g}$ were used for this study; 60 for the pilot study and 88 for the chronic toxicity test. 88 rats divided into eleven groups consisting of 8 rats each were used for the main experiment. Groups 1 and 2 served as control groups and received normal saline as placebo and $\mathbf{9 9 . 5 \%}$ dimethyl sulfoxide (DMSO) (Solvent control), respectively. Drugs were administered orally via a $1 \mathrm{ml}$ syringe. Animals were given three doses $\left(1 / 5^{\text {th }}, 1 / 10^{\text {th }}\right.$ and $\left.1 / 20^{\text {th }}\right)$ of the calculated $L D_{50}$ of $373 \mathrm{mg} / \mathrm{kg}$ and $75 \mathrm{mg} / \mathrm{kg}$ for disulfiram and copper gluconate respectively. Dosing was done daily with that of the combination given 12 hours apart. Blood samples were obtained via cardiac puncture on days 30, 45, 60 and 90 for analysis. Haematological parameters showed a significant $(p<0.05)$ dose- and time-dependent decrease in the packed cell volume, red blood cell count, white blood cell count and platelet count respectively. The results indicate bone marrow depression evidenced by anemia, leucopenia and thrombocytopenia in the experimental animals. The DSF/CG combination appears to exhibit a synergistic dose-dependent haematotoxicity.

\section{Keywords}

Disulfiram, Copper gluconate, Haematological Indices

\section{Introduction}

Disulfiram (Antabuse) (Figure 1), a drug used for the aversive therapy of alcoholism and copper gluconate are being repurposed for cancer chemotherapy. Disulfiram, used for several decades in the treatment of alcoholism, 
now shows promise as an anticancer drug and radio sensitizer. Disulfiram-induced cytotoxicity has been reported to be mediated by oxidative stress [1] [2], and this may be enhanced by the presence of copper [1]. Many tumours contain elevated levels of copper which render them selectively susceptible to disulfiram-induced toxicity [3]. Copper binding drugs inhibit proteasome activity [3] and generate reactive oxygen species (ROS) [4]. Disulfiram chelates copper, and it has been suggested that the disulfiram-copper complex is the toxic form of the drug [5]. Researchers have observed that in the presence of copper, disulfiram exhibits cytotoxic effects on a number of cancer cell lines. It is postulated that disulfiram, chemically a bis-N, N-diethyldithiocarbamate forms a carbamato complex with copper II ions in situ which inhibits the proteasome activity, instigating apoptosis and eventual cell death [5]. This research work set out to study the chronic toxicological effect of the DSF/CG combination on haematological parameters in rodents.<smiles>CCN(CC)C(=S)SSC(=S)N(CC)CC</smiles>

Figure 1. Chemical structure of Disulfiram (http://images.ddccdn.com/img/mol/DB00822.mol.t.jpg)

\section{Methodology}

148 Albino Swiss rats of both sexes weighing between $260 \mathrm{~g}$ - $300 \mathrm{~g}$ obtained from the Department of Pharmacology animal house were used for this study. 88 rats were used for the main experiment while 60 rats were used for the pilot study. The rats were bred and maintained under suitable conditions, allowed an acclimatization period of two (2) weeks, housed in hygienic cages in groups of four and allowed free access to feed obtained from vital feeds UAC PLC and water ad libitum. The beddings were changed and cages cleaned out on alternate days. Animals were handled according to Helsinki declaration on animal care. The animals were divided into 11 groups, each consisting of 8 rats each. The groups included those for treatment and the control groups. Drugs were administered orally via a $1 \mathrm{ml}$ syringe.

\subsection{Pilot Study}

Acute toxicity tests were done using the arithmetic method of Karber to determine the $\mathrm{LD}_{50}$ of disulfiram and copper gluconate. A total of 60 rats were used. This preliminary dose range finding test was done to determine the doses to be administered. Drugs were administered via the intra-peritoneal route. The Arithmetic method of Karber as adapted by (Patel, 2004) [6] was used as follows;

This method made use of the formula stated below:

$$
\mathrm{LD}_{50}=\mathrm{LD}_{100}-\sum\{a \times b\} / n
$$

where, $\mathrm{LD}_{50}=$ Median Lethal dose;

$\mathrm{LD}_{100}=$ Dose that kills $100 \%$ of the test animals;

$a=$ Dose difference;

$b=$ Mean mortality;

$n=$ group population.

\subsection{Chronic Toxicity Tests}

This study spanned 3 months and was domiciled in the Department of Pharmacology, University of Port Harcourt, Animal house and Laboratory. A dose and time dependent toxicological evaluation of the effects of disulfiram, copper gluconate and disulfiram and copper gluconate combination on the haematological profiles of rodents was evaluated. A total of 88 rats obtained from the Department of Pharmacology animal house were divided into eleven groups consisting of 8 rats each. Groups 1 and 2 served as control groups and the rats received normal saline as placebo and 99.5\% DMSO (Solvent control) respectively. Drugs were administered orally via a $1 \mathrm{ml}$ syringe. 
The test group rats were divided into groups 3, 4 and 5 consisting of 24 rats in each group. Drug administration was done orally for 90 days as follows:

Control group 1 rats received $1 \mathrm{ml}$ of normal saline orally daily for 90 days

Solvent control, group 2 received $0.5 \mathrm{ml}$ of DMSO orally daily for 90 days

Group 3a rats received $* 15 \mathrm{mg} / \mathrm{kg}$ of copper gluconate daily orally

Group $3 \mathrm{~b}$ rats received $* 7.5 \mathrm{mg} / \mathrm{kg}$ of copper gluconate daily orally

Group $3 \mathrm{c}$ rats received $* 3.75 \mathrm{mg} / \mathrm{kg}$ of copper gluconate daily orally

*doses were $1 / 5^{\text {th }}, 1 / 10^{\text {th }}$ and $1 / 20^{\text {th }}$ of the $\mathrm{LD}_{50}$ of Copper gluconate

Group 4a rats received ${ }^{\circ} 74.6 \mathrm{mg} / \mathrm{kg}$ of DSF and $* 15 \mathrm{mg} / \mathrm{kg}$ of copper gluconate daily orally

Group 4b rats received ${ }^{\circ} 37.3 \mathrm{mg} / \mathrm{kg}$ of DSF and $* 7.5 \mathrm{mg} / \mathrm{kg}$ of copper gluconate daily orally

Group 4c rats received ${ }^{\circ} 18.65 \mathrm{mg} / \mathrm{kg}$ of DSF and $* 3.75 \mathrm{mg} / \mathrm{kg}$ of copper gluconate daily orally

${ }^{\circ}$ Doses were $1 / 5^{\text {th }}, 1 / 10^{\text {th }}$ and $1 / 20^{\text {th }}$ of the $\mathrm{LD}_{50}$ of disulfiram (DSF)

*Doses were $1 / 5^{\text {th }}, 1 / 10^{\text {th }}$ and $1 / 20^{\text {th }}$ of the $\mathrm{LD}_{50}$ of copper gluconate

N/B The drug combination was given following the protocol of Grossman et al., 2011 [7].

Group 5a rats received ${ }^{\circ} 74.6 \mathrm{mg} / \mathrm{kg}$ of DSF daily orally

Group 5 b rats received ${ }^{\circ} 37.3 \mathrm{mg} / \mathrm{kg}$ of DSF daily orally

Group 5 c rats received ${ }^{\circ} 18.65 \mathrm{mg} / \mathrm{kg}$ of DSF daily orally

${ }^{\circ}$ Doses were $1 / 5^{\text {th }}, 1 / 10^{\text {th }}$ and $1 / 20^{\text {th }}$ of the $\mathrm{LD}_{50}$ of disulfiram (DSF)

\subsection{Collection of Samples}

Two animals per group were sacrificed under diethyl ether anaesthesia and blood samples were obtained with a $5 \mathrm{ml}$ syringe on days 30, 45, 60 and 90 for analysis via cardiac puncture. The Packed cell volume, red blood cell count, white blood cell count and platelets were analyzed using the auto haematology analyzer (BC 2800) made in China.

\subsection{Stock Solutions}

These were prepared from 99.5\% DMSO for disulfiram and distilled water for copper gluconate. Pure analytical grade samples, CAS No. 527-09-3 (98\% min purity) and CAS No. 97-77-8 (98\% min purity) obtained from Shijiazhuang Aopharm Import and Export Co. Limited China were used for the study.

\subsection{Ethical Approval}

This was obtained from the University of Port Harcourt Research Ethics Committee.

\subsection{Statistical Analysis}

This was done using graph pad prism 5 statistical package and ANOVA for comparison of the means of the various groups. Results are expressed as means \pm SEM. Test group results were compared with that of the control groups. A p-value $<0.05$ was considered significant.

\section{Results}

Table 1. $\mathrm{LD}_{50}$ determination of disulfiram (DSF).

\begin{tabular}{ccccc}
\hline DOSE $(\mathrm{mg} / \mathrm{kg})$ & NO. OF DEAD & MEAN DEAD (MD) & DOSE DIFF (DD) & MDXDD \\
\hline 200 & 0 & 0 & 0 & 0 \\
300 & 1 & 0.5 & 100 & 50 \\
350 & 2 & 1.5 & 50 & 125 \\
400 & 3 & 2.5 & 50 & 175 \\
450 & 4 & 3.5 & 50 & 225 \\
500 & 5 & 4.5 & 50 & 635 \\
TOTAL & & & & \\
\hline
\end{tabular}

$\mathrm{LD}_{50}=373 \mathrm{mg} / \mathrm{kg}$. 
Table 2. $\mathrm{LD}_{50}$ determination of copper gluconate (CG).

\begin{tabular}{ccccc}
\hline DOSE $(\mathrm{mg} / \mathrm{kg})$ & NO. OF DEAD & MEAN DEAD (MD) & DOSE DIFF (DD) & MD XDD \\
50 & 0 & 0 & 0 & 0 \\
60 & 1 & 0.5 & 10 & 5 \\
70 & 2 & 1.5 & 10 & 25 \\
80 & 3 & 2.5 & 10 & 35 \\
90 & 4 & 3.5 & 10 & 45 \\
100 & 5 & 4.5 & 10 & 125 \\
\hline
\end{tabular}

$\mathrm{LD}_{50}=75 \mathrm{mg} / \mathrm{kg}$.

Table 3. Effect of low dose DSF (18.65 mg/kg), CG (3.75 mg/kg) and DSF/CG (18.65/3.75 mg/kg) combination on PCV (\%).

\begin{tabular}{ccccc}
\hline & 30 DAYS & 45 DAYS & 60 DAYS & 90 DAYS \\
\hline CONTROL 1 & $48.67 \pm 1.856$ & $50.00 \pm 2.000$ & $49.33 \pm 1.333$ & $52.67 \pm 1.764$ \\
DSF & $42.33 \pm 1.453$ & $42.67 \pm 3.712$ & $42.67 \pm 3.712$ & $44.33 \pm 3.480$ \\
CG & $40.00 \pm 1.155^{*}$ & $39.33 \pm 2.906^{*}$ & $39.33 \pm 2.906^{*}$ & $39.33 \pm 2.906^{*}$ \\
DSF/CG & $38.67 \pm 1.333^{*}$ & $38.00 \pm 3.786^{*}$ & $38.00 \pm 3.786^{*}$ & $32.00 \pm 4.619^{*}$ \\
\hline
\end{tabular}

Results are expressed as mean $\pm \mathrm{SEM}$, the superscript $\left({ }^{*}\right)$ means significant difference with respect to control at $\mathrm{p}<0.05$ (ANOVA).

Table 4. Effect of medium dose DSF (37.3 mg/kg), CG (7.5 mg/kg), DSF/CG (37.3/7.5 mg/kg) combination on PCV (\%).

\begin{tabular}{ccccc}
\hline & 30 DAYS & 45 DAYS & 60 DAYS & 90 DAYS \\
\hline CONTROL 1 & $52.67 \pm 0.667$ & $52.67 \pm 0.667$ & $50.27 \pm 0.176$ & $50.07 \pm 0.067$ \\
DSF & $46.67 \pm 1.764^{*}$ & $47.33 \pm 1.764^{*}$ & $41.00 \pm 2.646^{*}$ & $41.00 \pm 2.646^{*}$ \\
CG & $47.33 \pm 1.764^{*}$ & $44.00 \pm 2.309^{*}$ & $42.00 \pm 2.309^{*}$ & $42.00 \pm 2.309^{*}$ \\
DSF/CG & $43.33 \pm 2.404^{*}$ & $41.33 \pm 2.906^{*}$ & $40.33 \pm 3.283^{*}$ & $41.00 \pm 2.646^{*}$ \\
\hline
\end{tabular}

Results are expressed as mean \pm SEM, the superscript $\left(^{*}\right)$ means significant difference with respect to control at $\mathrm{p}<0.05$ (ANOVA).

Table 5. Effect of high dose DSF (74.6 mg/kg), CG (15 mg/kg) and DSF/CG (74.6/15 mg/kg) combination on PCV (\%).

\begin{tabular}{ccccc}
\hline & 30 DAYS & 45 DAYS & 60 DAYS & 90 DAYS \\
\hline CONTROL 1 & $50.07 \pm 1.097$ & $52.67 \pm 0.667$ & $52.67 \pm 0.667$ & $52.00 \pm 1.155$ \\
DSF & $40.33 \pm 3.283^{*}$ & $39.00 \pm 4.583^{*}$ & $39.00 \pm 4.583^{*}$ & $40.33 \pm 3.283^{*}$ \\
CG & $38.67 \pm 4.667^{*}$ & $40.67 \pm 3.528^{*}$ & $40.67 \pm 3.528^{*}$ & $44.33 \pm 2.186^{*}$ \\
DSF/CG & $42.33 \pm 3.180^{*}$ & $41.33 \pm 3.712^{*}$ & $40.33 \pm 4.177^{*}$ & $44.67 \pm 1.764^{*}$ \\
\hline
\end{tabular}

Results are expressed as mean \pm SEM, the superscript $\left(^{*}\right)$ means significant difference with respect to control at $\mathrm{p}<0.05$ (ANOVA).

Table 6. Effect of low dose DSF (18.6 mg/kg), CG $(3.75 \mathrm{mg} / \mathrm{kg})$, DSF/CG $(18.6 / 3.75 \mathrm{mg} / \mathrm{kg})$ combination on RBC $\left(\times 10^{12}\right)$.

\begin{tabular}{ccccc}
\hline & 30 DAYS & 45 DAYS & 60 DAYS & 90 DAYS \\
\hline CONTROL 1 & $25.67 \pm 0.667$ & $26.67 \pm 0.667$ & $27.67 \pm 1.202$ & $31.00 \pm 0.5774$ \\
DSF & $20.33 \pm 0.333^{*}$ & $22.00 \pm 1.528^{*}$ & $22.00 \pm 1.528^{*}$ & $22.00 \pm 1.528^{*}$ \\
CG & $19.33 \pm 0.667^{*}$ & $20.67 \pm 1.333^{*}$ & $20.67 \pm 1.333^{*}$ & $20.67 \pm 1.333^{*}$ \\
DSF/CG & $19.07 \pm 0.581^{*}$ & $19.40 \pm 0.872^{*}$ & $19.40 \pm 0.872^{*}$ & $19.40 \pm 0.872^{*}$ \\
\hline
\end{tabular}

Results are expressed as mean \pm SEM, the superscript ( ${ }^{*}$ ) means significant difference with respect to control at $\mathrm{p}<0.05$ (ANOVA). 
Table 7. Effect of medium dose DSF (37.3 mg/kg), CG (7.5 mg/kg) and DSF/CG (37.3/7.5 mg/kg) combination on RBC $\left(\times 10^{12}\right)$.

\begin{tabular}{ccccc}
\hline & 30 DAYS & 45 DAYS & 60 DAYS & 90 DAYS \\
\hline CONTROL 1 & $32.00 \pm 1.155$ & $9.633 \pm 0.067$ & $9.633 \pm 0.067$ & $8.333 \pm 0.167$ \\
DSF & $26.33 \pm 1.202^{*}$ & $6.233 \pm 0.145^{*}$ & $6.233 \pm 0.145^{*}$ & $6.233 \pm 0.145^{*}$ \\
CG & $24.00 \pm 2.309^{*}$ & $6.167 \pm 0.203^{*}$ & $6.167 \pm 0.203^{*}$ & $6.167 \pm 0.203^{*}$ \\
DSF/CG & $24.00 \pm 2.309^{*}$ & $5.867 \pm 0.353^{*}$ & $5.800 \pm 0.416^{*}$ & $5.800 \pm 0.416^{*}$ \\
\hline
\end{tabular}

Results are expressed as mean \pm SEM, the superscript $\left({ }^{*}\right)$ means significant difference with respect to control at $\mathrm{p}<0.05$ (ANOVA).

Table 8. Effect of high dose DSF (74.6 mg/kg), CG (15 mg/kg) and DSF/CG (74.6/15 mg/kg) combination on RBC $\left(\times 10^{12}\right)$.

\begin{tabular}{ccccc}
\hline & 30 DAYS & 45 DAYS & 60 DAYS & 90 DAYS \\
\hline CONTROL 1 & $8.333 \pm 0.167$ & $9.640 \pm 0.074$ & $9.640 \pm 0.074$ & $9.833 \pm 0.167$ \\
DSF & $6.167 \pm 0.203^{*}$ & $6.167 \pm 0.203^{*}$ & $6.100 \pm 0.265^{*}$ & $5.833 \pm 0.524^{*}$ \\
CG & $5.967 \pm 0.393^{*}$ & $5.967 \pm 0.393^{*}$ & $5.900 \pm 0.458^{*}$ & $5.567 \pm 0.788^{*}$ \\
DSF/CG & $5.800 \pm 0.416^{*}$ & $5.800 \pm 0.416^{*}$ & $5.733 \pm 0.481^{*}$ & $5.467 \pm 0.742^{*}$
\end{tabular}

Results are expressed as mean \pm SEM, the superscript $\left({ }^{*}\right.$ ) means significant difference with respect to control at $\mathrm{p}<0.05$ (ANOVA).

Table 9. Effect of low dose DSF (18.65 mg/kg), CG (3.75 mg/kg) and DSF/CG (18.65/3.75 mg/kg) combination on WBC $(\times 1000)$.

\begin{tabular}{|c|c|c|c|c|}
\hline & 30 DAYS & 45 DAYS & 60 DAYS & 90 DAYS \\
\hline CONTROL 1 & $10.70 \pm 0.520$ & $10.70 \pm 0.520$ & $10.73 \pm 0.536$ & $11.63 \pm 0.664$ \\
\hline DSF & $9.400 \pm 0.208$ & $9.000 \pm 1.155$ & $9.000 \pm 1.155$ & $9.000 \pm 1.155$ \\
\hline CG & $8.667 \pm 0.203^{*}$ & $8.667 \pm 0.203^{*}$ & $8.667 \pm 0.203^{*}$ & $8.667 \pm 0.203^{*}$ \\
\hline $\mathrm{DSF} / \mathrm{CG}$ & $7.433 \pm 0.449^{*}$ & $7.100 \pm 0.737^{*}$ & $7.100 \pm 0.737^{*}$ & $7.100 \pm 0.737^{*}$ \\
\hline
\end{tabular}

Results are expressed as mean \pm SEM, the superscript $\left(^{*}\right)$ means significant difference with respect to control at $\mathrm{p}<0.05$ (ANOVA).

Table 10. Effect of medium dose DSF (37.3 mg/kg), CG (7.5 mg/kg) and DSF/CG (37.3/7.5 mg/kg) combination on WBC $(\times 1000)$.

\begin{tabular}{|c|c|c|c|c|}
\hline & 30 DAYS & 45 DAYS & 60 DAYS & 90 DAYS \\
\hline CONTROL 1 & $14.67 \pm 1.764$ & $15.33 \pm 0.667$ & $11.97 \pm 0.328$ & $11.97 \pm 0.328$ \\
\hline DSF & $9.000 \pm 1.155$ & $9.000 \pm 1.155^{*}$ & $5.533 \pm 0.291^{*}$ & $5.533 \pm 0.291^{*}$ \\
\hline CG & $8.667 \pm 0.203^{*}$ & $8.667 \pm 0.203^{*}$ & $6.000 \pm 0.231^{*}$ & $6.000 \pm 0.231^{*}$ \\
\hline DSF/CG & $7.100 \pm 0.737^{*}$ & $7.100 \pm 0.737^{*}$ & $5.200 \pm 0.603^{*}$ & $5.200 \pm 0.603^{*}$ \\
\hline
\end{tabular}

Results are expressed as mean \pm SEM, the superscript $\left(^{*}\right)$ means significant difference with respect to control at $\mathrm{p}<0.05$ (ANOVA).

Table 11. Effect of high dose DSF (74.6 mg/kg), CG (15 mg/kg), DSF/CG (74.6/15 mg/kg) combination on WBC (×1000).

\begin{tabular}{|c|c|c|c|c|}
\hline & 30 DAYS & 45 DAYS & 60 DAYS & 90 DAYS \\
\hline CONTROL 1 & $11.97 \pm 0.328$ & $11.67 \pm 0.167$ & $11.50 \pm 0.289$ & $11.50 \pm 0.289$ \\
\hline DSF & $5.533 \pm 0.291^{*}$ & $5.533 \pm 0.291^{*}$ & $5.533 \pm 0.291^{*}$ & $5.533 \pm 0.291^{*}$ \\
\hline CG & $5.933 \pm 0.291^{*}$ & $5.933 \pm 0.291^{*}$ & $5.800 \pm 0.416^{*}$ & $5.533 \pm 0.677^{*}$ \\
\hline $\mathrm{DSF} / \mathrm{CG}$ & $5.200 \pm 0.603^{*}$ & $5.367 \pm 0.437^{*}$ & $5.200 \pm 0.603^{*}$ & $5.133 \pm 0.669^{*}$ \\
\hline
\end{tabular}

Results are expressed as mean \pm SEM, the superscript $\left(^{*}\right)$ means significant difference with respect to control at $\mathrm{p}<0.05$ (ANOVA). 
Table 12. Effect of low dose DSF (18.65 mg/kg), CG (3.75 mg/kg) and DSF/CG (18.65/3.75 mg/kg) combination on PLT $(\times 1000)$.

\begin{tabular}{ccccc}
\hline & 30 DAYS & 45 DAYS & 60 DAYS & 90 DAYS \\
\hline CONTROL 1 & $471.3 \pm 1.856$ & $474.3 \pm 2.603$ & $480.0 \pm 11.55$ & $461.7 \pm 1.667$ \\
DSF & $433.3 \pm 8.819^{*}$ & $440.0 \pm 11.55^{*}$ & $413.3 \pm 17.64^{*}$ & $420.0 \pm 11.55^{*}$ \\
CG & $423.3 \pm 12.02^{*}$ & $433.3 \pm 13.33^{*}$ & $426.7 \pm 13.33^{*}$ & $388.3 \pm 16.41^{*}$ \\
DSF/CG & $403.3 \pm 8.819^{*}$ & $396.7 \pm 26.03^{*}$ & $396.7 \pm 26.03^{*}$ & $350.0 \pm 28.87^{*}$ \\
\hline
\end{tabular}

Results are expressed as mean \pm SEM, the superscript $\left(^{*}\right)$ means significant difference with respect to control at $\mathrm{p}<0.05$ (ANOVA).

Table 13. Effect of medium dose DSF (37.3 mg/kg), CG (7.5 mg/kg) and DSF/CG (37.3/7.5 mg/kg) combination on PLT $(\times 1000)$.

\begin{tabular}{|c|c|c|c|c|}
\hline & 30 DAYS & 45 DAYS & 60 DAYS & 90 DAYS \\
\hline CONTROL 1 & $512.0 \pm 6.110$ & $631.7 \pm 9.280$ & $543.3 \pm 8.819$ & $563.3 \pm 18.56$ \\
\hline DSF & $420.0 \pm 11.55^{*}$ & $420.0 \pm 11.55^{*}$ & $446.7 \pm 29.06^{*}$ & $460.0 \pm 30.55^{*}$ \\
\hline CG & $388.3 \pm 16.41^{*}$ & $388.3 \pm 16.41^{*}$ & $380.0 \pm 11.55^{*}$ & $380.0 \pm 11.55^{*}$ \\
\hline DSF/CG & $350.0 \pm 28.87^{*}$ & $350.0 \pm 28.87^{*}$ & $350.0 \pm 28.87^{*}$ & $350.0 \pm 28.87^{*}$ \\
\hline
\end{tabular}

Results are expressed as mean \pm SEM, the superscript $\left(^{*}\right)$ means significant difference with respect to control at $\mathrm{p}<0.05$ (ANOVA).

Table 14. Effect of high dose DSF (74.6 mg/kg), CG (15 mg/kg) and DSF/CG (74.6/15 mg/kg) combination on PLT $(\times 1000)$.

\begin{tabular}{|c|c|c|c|c|}
\hline & 30 DAYS & 45 DAYS & 60 DAYS & 90 DAYS \\
\hline CONTROL 1 & $563.3 \pm 18.56$ & $513.3 \pm 6.667$ & $511.7 \pm 4.410$ & $518.3 \pm 7.265$ \\
\hline DSF & $460.0 \pm 30.55^{*}$ & $416.7 \pm 16.67^{*}$ & $416.7 \pm 33.83^{*}$ & $416.7 \pm 33.83^{*}$ \\
\hline CG & $380.0 \pm 12.00^{*}$ & $373.3 \pm 17.64^{*}$ & $366.7 \pm 24.04^{*}$ & $360.0 \pm 30.55^{*}$ \\
\hline DSF/CG & $350.0 \pm 28.87^{*}$ & $346.7 \pm 31.80^{*}$ & $343.3 \pm 34.80^{*}$ & $333.3 \pm 44.10^{*}$ \\
\hline
\end{tabular}

Results are expressed as mean \pm SEM, the superscript $\left(^{*}\right)$ means significant difference with respect to control at $\mathrm{p}<0.05$ (ANOVA).

\section{Discussion}

The median lethal dose $\left(\mathrm{LD}_{50}\right)$ of a drug is that dose that kills $50 \%$ of the study population and serves as a general indicator of a drug's acute toxicity. For disulfiram, our study revealed an $L D_{50}$ of $373 \mathrm{mg} / \mathrm{kg}$ (Table 1) and for copper gluconate an $\mathrm{LD}_{50}$ of $75 \mathrm{mg} / \mathrm{kg}$ was obtained (Table 2).

Low dose disulfiram had no significant $(\mathrm{p}>0.05$ ) effect on the packed cell volume (PCV) compared to the control, but copper gluconate and disulfiram/copper gluconate combination produced reductions in PCV values that were significant at $\mathrm{p}<0.05$ when compared to the control (Table 3). The finding of the significant effect of the combination may not be unconnected with the synergistic actions of the two drugs when combined.

Disulfiram, copper gluconate and disulfiram/copper gluconate combination at medium and high doses produced reductions in packed cell volume (PCV) that were significant $(\mathrm{p}<0.05)$ when compared to the control (Table 4 and Table 5). The results were in agreement with the findings of Al Naimi et al. [8] whose work on $\mathrm{CuSo}_{4}$ in rats revealed a significant decrease in PCV values.

The reductions produced in the red blood cell (RBC) fractions by disulfiram, copper gluconate and their combination at low, medium and high doses were all significant $(\mathrm{p}<0.05)$ when compared to the control (Tables 68). The results were also in agreement with the findings of Al Naimi et al. [8] whose work on $\mathrm{CuSo}_{4}$ in rats revealed a significant decrease in RBC counts and PCV values with marked decrease in haemoglobin concentration suggestive of chronic blood loss due to haemolytic anaemia. Adams et al. (1979) [9] in their research, reported marked reduction in the deformability of the RBCs as well as marked increases in membrane permeability and osmotic fragility. In 1977 Adam and Wasfi, [10] reported that Copper induced formation and subsequent degradation of peroxides from the membrane lipids of the RBCs which may be a critical factor in altering mem- 
brane integrity that leads to hemolysis. Other researchers assert that excess copper intake produces anaemia by interfering with iron transport and/or metabolism [11] [12]. These observations may explain the recorded findings of this current investigation

This study's findings, indicate that at low dose, copper gluconate and disulfiram/copper gluconate combination produced marked reductions in white blood count (WBC) values that were significant $(\mathrm{p}<0.05)$ when compared with control (Table 9). Disulfiram at medium dose produced reductions in WBC values that were significant ( $<20.05$ ) only on day 45, 60 and 90, while copper gluconate and disulfiram/copper gluconate combination produced WBC reductions that were significant $(\mathrm{p}<0.05)$ throughout the test period (Table 10). However, at high dose, disulfiram, copper gluconate and disulfiram/copper gluconate combination produced marked reductions in white blood count (WBC) values that were significant $(\mathrm{p}<0.05)$ when compared with the control (Table 11) throughout the duration of the study. These findings were not surprising as it is known that the effects of high-dose ingestion of heavy metals include degenerative changes in the liver and kidneys and that at very high doses these heavy metals can cause leukopenia and marked hypoplasia or aplasia of the bone marrow. The result of this current investigation on WBC value is however at variance with the findings of Beddard et al., 2000 [13] who found significant increase in WBC count of experimental animals given different doses of $\mathrm{CuSo}_{4} \cdot \mathrm{H}_{2} \mathrm{O}$ when compared with the control. A finding he described as unusual neutrophilia. Beddard and his co-investigators further explained that the neutrophilia could have been produced by inflammatory stimuli coming from the damaged liver cells.

Disulfiram, copper gluconate and disulfiram/copper gluconate combination produced marked reduction in platelet count that was significant $(\mathrm{p}<0.05)$ at low, medium and high doses when compared with the control (Tables 12-14). This agrees with the findings of Beddard et al., 2000 [13] who also reported a significant decrease in platelet count in their study of effects of $\mathrm{CuSo}_{4}$ in rats. It is believed that secondary thrombocytopenia resulting from poisoning with heavy metal causes interference with clotting and haemorrhage [13]. It has been reported by Turnlund et al., 2004 [14], that long-term high intake of copper can result in adverse effects on immune function. This perhaps explains the significant $(\mathrm{p}<0.05)$ decrease recorded in the different haematological parameters studied. As the level of reduction obtained in this study on the different components of the blood would adversely reduce immunity.

\section{Conclusion}

This current investigation has clearly shown that, disulfiram/copper gluconate combination produced bone marrow depression as evidenced by anaemia (low PCV), leucocytopenia (low WBC count) and thrombocytopenia (low Platelet count) in the experimental animals following chronic use. The importance of the sequel effects of bone marrow depression on the overall health of an organism need not be overemphasized; therefore, we believe that there is a synergistic toxicological effect when disulfiram and copper gluconate are combined. While these effects appear mild at low and medium doses and can be advisedly used with caution, at high doses this combination is highly toxic and should therefore be used with extreme caution.

\section{Acknowledgements}

The authors are grateful to Prof. O. A. Georgewill and Dr. Dawaye A. Georgewill for their useful contributions.

\section{References}

[1] Chen, S.H., Liu, S.H., Liang, Y.C., Lin, J.K. and Lin-Shiau, S.Y. (2001) Oxidative Stress and c-Junamino-Terminal Kinase Activation Involved in Apoptosis of Primary Astrocytes Induced by Disulfiram-Cu21 Complex. European Journal of Pharmacology, 414, 177-188. http://dx.doi.org/10.1016/S0014-2999(01)00792-0

[2] Cen, D., Gonzalez, R.I., Buckmeier, J.A., Kahlon, R.S., Tohidian, N.B. and Meyskens Jr., F.L. (2002) Disulfiram Induces Apoptosis in Human Melanoma Cells: A Redox-Related Process. Molecular Cancer Therapeutics, 1, 197-204.

[3] Daniel, K.G., Chen, D., Yan, B. and Dou, Q.P. (2007) Copper-Binding Compounds as Proteasome Inhibitors and Apoptosis Inducers in Human Cancer. Frontiers in Bioscience, 12, 135-144.

[4] Gupte, A. and Mumper, J. (2009) Elevated Copper and Oxidative Stress in Cancer Cells as a Target for Cancer Treatment. Cancer Treatment Reviews, 35, 32-46. http://dx.doi.org/10.1016/j.ctrv.2008.07.004

[5] Chen, D., Cui, Q.C., Yang, H. and Dou, Q.P. (2006) Disulfiram, a Clinically Used Anti-Alcoholism Drug and Copper-Binding Agent, Induces Apoptotic Cell Death in Breast Cancer Cultures and Xenograftsvia Inhibition of the Pro- 
teasome Activity. Cancer Research, 66, 10425-10433. http://dx.doi.org/10.1158/0008-5472.CAN-06-2126

[6] Patel, S. (2004) Demonstration of Karber's Method of LD50 Determination. Journal of Chemical Pharmaceutical Research. http://m.authorstream.com/presentation/patelcharmi91-1826002-methods-determineLD50

[7] Grossmann, K.F., Blankenship, M.B., Akerley, W., Terrazas, M.C., Kosak, K.M., Boucher, K.M., Buys, S.S., Jones, K., Werner, T.L., Agarwal, N., Weis, J., Sharma, S., Ward, J. and Shami, P.J. (2011) Abstract 1308: A Phase I Clinical Study Investigating Disulfiram and Copper Gluconate in Patients with Advanced Treatment-Refractory Solid Tumors Involving the Liver. Cancer Research, 71. http://dx.doi.org/10.1158/1538-7445.AM2011-1308

[8] Al-Naimi, R.A., Al-Tayar, N.H., Alsoufi, L.A.M. and Al-Taae, E.H.Y. (2013) Hematological and Biochemical Evaluation after Different Orally Doses of Copper Sulfate in Rats. The Iraqi Journal of Veterinary Medicine, 38, 83-91.

[9] Adams, K.F., Johnson, G., Hornowski, K.E. and Lineberger, T.H. (1979) The Effect of Copper on Erythrocytes Deformability: A Possible Mechanism of Hemolysis in Acute Copper Intoxication. 23. Biochimica et Biophysica Acta, 550, 279-287.

[10] Adam, S.E.I. and Wasfi, I.A. (1977) Chronic Copper Toxicity in Nubain Goats. Journal of Comparative Pathology, 87, 623-627.

[11] Ralph, A. and McArdle, H.J. (2001) Copper Metabolism and Requirements in the Pregnant Mother, Her Fetus, and Children. International Copper Association, New York.

[12] International Programme on Chemical Safety (1998) Environmental Health Criteria No. 200: Copper. World Health Organization, Geneva.

[13] Bedard, K., Fuentealba, I.C. and Cribb, A. (2000) The Long Evans Cinnamon (LEC) Rat Develops Hepatocellular Damage in the Absence of Antimicrosomal Antibodies. Toxicology, 146, 101-109.

[14] Turnlund, J.R., Jacob, R.A., Keen, C.L., et al. (2004) Long-Term High Copper Intake: Effects on Indexes of Copper Status, Antioxidant Status, and Immune Function in Young Men. The American Journal of Clinical Nutrition, 79, 1037-1044. 
Scientific Research Publishing (SCIRP) is one of the largest Open Access journal publishers. It is currently publishing more than 200 open access, online, peer-reviewed journals covering a wide range of academic disciplines. SCIRP serves the worldwide academic communities and contributes to the progress and application of science with its publication.

Other selected journals from SCIRP are listed as below. Submit your manuscript to us via either submit@scirp.org or Online Submission Portal.
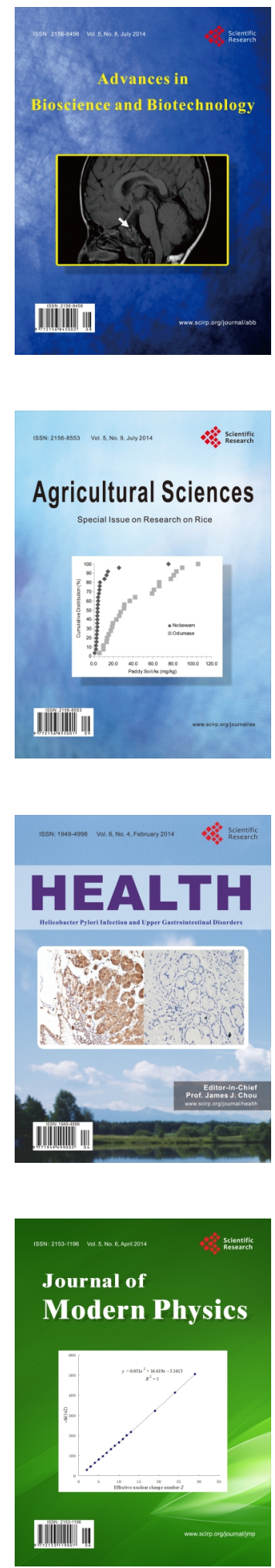
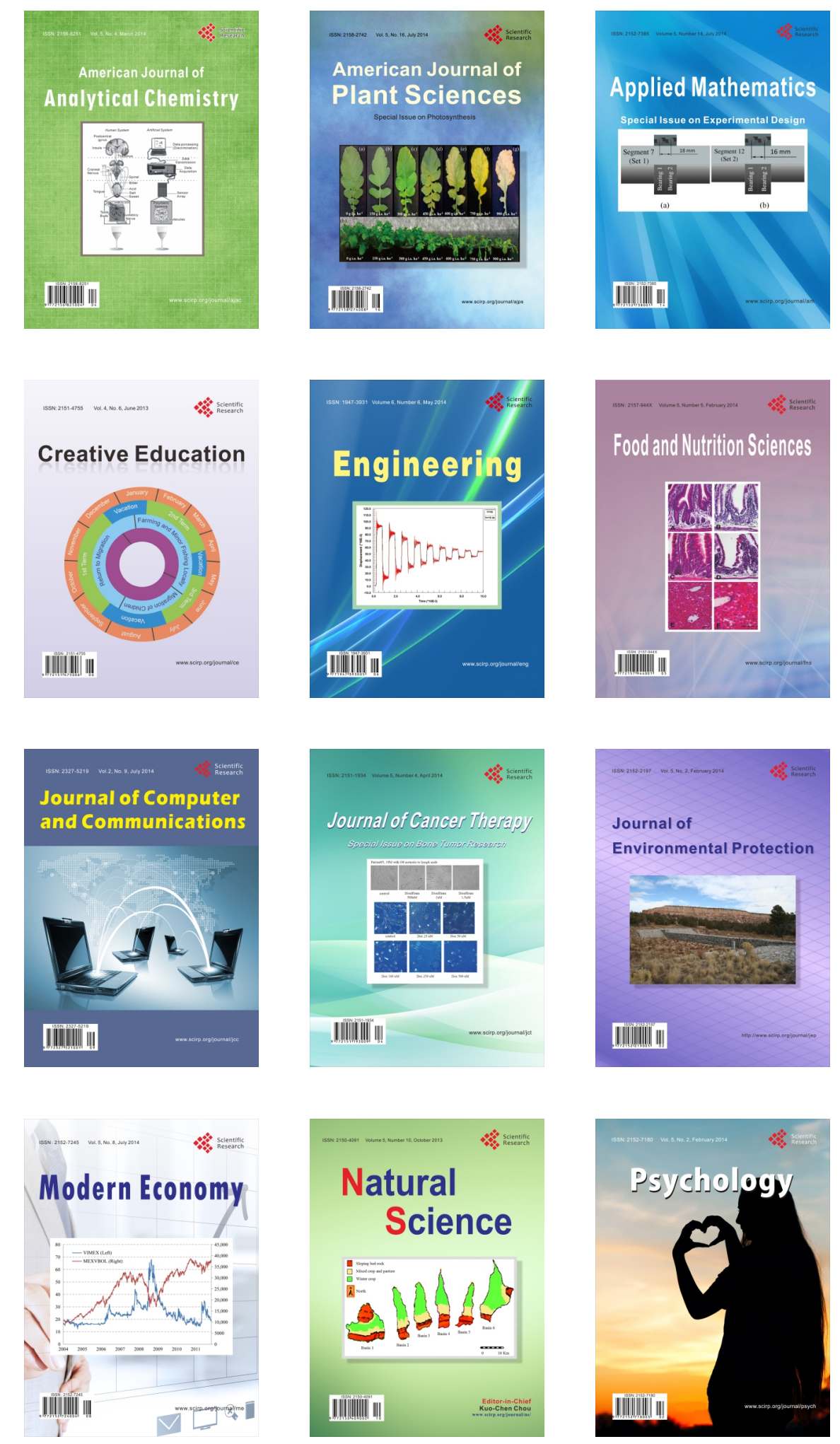